\title{
Multi-decadal analysis of root-zone soil moisture applying the exponential filter across CONUS
}

\author{
Kenneth J. Tobin ${ }^{1}$, Roberto Torres ${ }^{1}$, Wade T. Crow $^{2}$, and Marvin E. Bennett ${ }^{1}$ \\ ${ }^{1}$ Texas A\&M International University, Center for Earth and Environmental Studies, Laredo, TX, USA \\ ${ }^{2}$ United States Department of Agriculture, Agricultural Research Service Hydrology and Remote Sensing Laboratory, \\ Beltsville, MD, USA
}

Correspondence to: Kenneth J. Tobin (ktobin@tamiu.edu)

Received: 1 March 2017 - Discussion started: 11 April 2017

Revised: 6 July 2017 - Accepted: 7 July 2017 - Published: 7 September 2017

\begin{abstract}
This study applied the exponential filter to produce an estimate of root-zone soil moisture (RZSM). Four types of microwave-based, surface satellite soil moisture were used. The core remotely sensed data for this study came from NASA's long-lasting AMSR-E mission. Additionally, three other products were obtained from the European Space Agency Climate Change Initiative (CCI). These datasets were blended based on all available satellite observations (CCI-active, CCI-passive, and CCI-combined). All of these products were $0.25^{\circ}$ and taken daily. We applied the filter to produce a soil moisture index (SWI) that others have successfully used to estimate RZSM. The only unknown in this approach was the characteristic time of soil moisture variation $(T)$. We examined five different eras (1997-2002; 20022005; 2005-2008; 2008-2011; 2011-2014) that represented periods with different satellite data sensors. SWI values were compared with in situ soil moisture data from the International Soil Moisture Network at a depth ranging from 20 to $25 \mathrm{~cm}$. Selected networks included the US Department of Energy Atmospheric Radiation Measurement (ARM) program $(25 \mathrm{~cm})$, Soil Climate Analysis Network (SCAN; $20.32 \mathrm{~cm}$ ), SNOwpack TELemetry (SNOTEL; $20.32 \mathrm{~cm}$ ), and the US Climate Reference Network (USCRN; $20 \mathrm{~cm}$ ). We selected in situ stations that had reasonable completeness. These datasets were used to filter out periods with freezing temperatures and rainfall using data from the Parameter elevation Regression on Independent Slopes Model (PRISM). Additionally, we only examined sites where surface and root-zone soil moisture had a reasonably high lagged $r$ value $(r>0.5)$.

The unknown $T$ value was constrained based on two approaches: optimization of root mean square error (RMSE)
\end{abstract}

and calculation based on the normalized difference vegetation index (NDVI) value. Both approaches yielded comparable results; although, as to be expected, the optimization approach generally outperformed NDVI-based estimates. The best results were noted at stations that had an absolute bias within $10 \%$. SWI estimates were more impacted by the in situ network than the surface satellite product used to drive the exponential filter. The average Nash-Sutcliffe coefficients (NSs) for ARM ranged from -0.1 to 0.3 and were similar to the results obtained from the USCRN network (0.2$0.3)$. NS values from the SCAN and SNOTEL networks were slightly higher $(0.1-0.5)$. These results indicated that this approach had some skill in providing an estimate of RZSM. In terms of RMSE (in volumetric soil moisture), ARM values actually outperformed those from other networks (0.020.04). SCAN and USCRN RMSE average values ranged from 0.04 to 0.06 and SNOTEL average RMSE values were higher $(0.05-0.07)$. These values were close to 0.04 , which is the baseline value for accuracy designated for many satellite soil moisture missions.

\section{Introduction}

Soil moisture is one of the most difficult hydrologic variables to either monitor or model (Lettenmaier et al., 2015). Understanding soil moisture dynamics is critical to support many diverse applications in hydrology, meteorology, and agriculture. In the agricultural sector, a fundamental limiting factor that constrains crop productivity is root-zone soil moisture (RZSM). Understanding root-zone moisture dynamics 
is important also from a water resource standpoint and is a valuable measure in drought monitoring (Bolten et al., 2010; Bolten and Crow, 2012). The dimensions of RZSM also impact other systems beyond the hydrologic cycle, most notably with the quantification of carbon fluxes within soils. Therefore, direct sensing of RZSM dynamics will bring us closer to a truer understanding of the carbon soil pool, with obvious implications for future climate change.

Given the importance of RZSM to agricultural and other applications, more effort is needed to understand the impacts of climate change associated with this critical variable. The National Aeronautics and Space Administration (NASA), European Space Agency (ESA), and other governments across the world have had a long history of supporting missions that generate remotely sensed surface soil moisture, including the Scanning Multichannel Microwave Radiometer (SMMR), the Special Sensor Microwave Imager (SSM/I), Tropical Rainfall Measurement Mission (TRMM), Advanced Microwave Scanning Radiometer-Earth Observing System (AMSR-E), Soil Moisture and Ocean Salinity (SMOS), Soil Moisture Active Passive (SMAP), scatterometers on the European remote sensing satellites, which includes scatterometer (SCAT) and the advanced scatterometer (ASCAT) to name only a few (e.g., Lakshmi et al., 1997; Wagner et al., 1999; Kerr et al., 2001; Jackson et al., 2002; Hutchinson, 2003; Njoku et al., 2003; McCabe et al., 2005; Owe et al., 2008; Entekhabi et al., 2010). Passive microwave soil moisture estimates, like AMSR-E-measured horizontal and vertical polarization temperatures in several wavelengths, which include $6.6 / 6.9 \mathrm{GHz}$ (C band), $10.7 \mathrm{GHz}$ (X band), and $19.3 \mathrm{GHz}$ (Ku band). In addition, the vertical polarization is examined at $36.5 / 37.0 \mathrm{GHz}$ (Ka band). An advantage of the more recent SMOS and SMAP missions is that they operate at a lower frequency $1.2 / 1.4 \mathrm{GHz}$ ( $\mathrm{L}$ band), which has great penetrative power, especially in highly vegetated areas. In terms of the active sensors, both SCAT and ASCAT operated at $5.3 \mathrm{GHz}$ (C band) and have a similar design philosophy. These sensors make sequential observations of the backscattering coefficient with six sideways-looking antennas and make sequential observations of the backscattering coefficient using three polarizing antennas.

Liu et al. (2012) described the development of two extensively validated surface soil moisture products. These products were created using a harmonized dataset based on all available soil moisture retrievals: one from the Vienna University of Technology (TU Wien) based on active microwave observations (Wagner et al., 2003; Bartalis et al., 2007) and one from the Vrije Universiteit Amsterdam (VUA), in collaboration with the NASA Goddard Space Flight Center Hydrological Sciences Laboratory, based on passive microwave observations (Owe et al., 2008). This effort was a part of the ESA Climate Change Initiative (CCI). The harmonization of these datasets incorporated the advantages of both microwave techniques and spanned the entire period from 1978 onward. This effort is unlike NOAA's Soil Moisture Oper- ational Products System (SMOPS), which was a long-term record of soil moisture based on only passive microwave data.

A long-standing goal of the soil remote sensing community is to develop techniques that can observe changes in RZSM at depths greater than $10 \mathrm{~cm}$, because all of the missions described above are confined to sensing moisture only within the top $5 \mathrm{~cm}$ of the profile. In 2015, NASA launched the SMAP mission that had the potential to combine the advantages of passive and active microwave retrievals to estimate soil moisture dynamics at depth. Unfortunately, early on in this mission, the satellite's radar failed. Despite this setback, NASA had invested considerable resources into the development of an ensemble Kalman filter (EnKF)-based level 4 RZSM product for SMAP (Reichle et al., 2016) and the development of lower-frequency airborne radar systems for deeper penetration of the soil column (via the EV-1 AirMOSS project). While this work is to be commended, the limited time availability of these products precludes their use for long-term climatic trend studies.

This study used the exponential filter to leverage the longer-duration CCI surface soil moisture record to produce a record of RZSM that can be compared over almost two decades (1997-2014). Wagner et al. (1999) developed the exponential filter to examine soil moisture trends from $\mathrm{Eu}-$ ropean remote sensing (ERS) scatterometer data focusing on Ukraine. A later refinement of this filter included the development of a recursive version that had the virtue of a greater ease of implementation (Albergel et al., 2008). In recent years, several authors have produced RZSM estimates using the exponential filter and have conducted comparisons at a range of spatial scales (Ford et al., 2014; Manfreda et al., 2014; Qiu et al., 2014; Peterson et al., 2016; Kedzior and Zawadzki, 2016). At the heart of the exponential filter method is the assumption of hydrologic equilibrium within the soil profile that makes it possible to estimate RZSM by using only surface measurements, provided that soil physical properties are known. This method also assumes that there is no loss from the root zone due to transpiration. Transfer of soil moisture from the surface to the root zone is controlled by a pseudo-diffusivity term that allows both positive and negative fluxes from and to the deep layer. This approach overcame a limitation of the EnKF approach in that data assimilation is not dependent on obtaining data from a land surface model, in which there can be significant uncertainty in terms of the model parameters used to constrain water and energy balances (Kumar et al., 2009). This study presents the results of the application of the exponential filter produced using four satellite soil moisture products from 1997 to 2014 focusing on the continental United States (CONUS). As such, this work represents a unique application of the exponential filter over a multi-decadal timescale, which is only afforded by the long-duration CCI record. 
Table 1. Observation eras from 1997 to 2014.

\begin{tabular}{lll}
\hline Era & Description & Time range \\
\hline 1 & Pre-AMSR-E & 27 November 1997-18 June 2002 \\
2 & Early AMSR-E & 19 June 2002-30 June 2005 \\
3 & Middle AMSR-E & 1 July 2005-30 June 2008 \\
4 & Late AMSR-E & 1 July 2008-3 October 2011 \\
5 & Post-AMSR-E & 4 October 2011-31 December 2014 \\
\hline
\end{tabular}

\section{Data}

\subsection{Era definitions}

The data examined in this study span over 17 years. As such, we compared soil moisture produced by the exponential filter over five roughly equal eras (3-4.5 years), which were defined based on the available satellite retrievals during each era (see Liu et al., 2012). These eras included 27 November 1997-18 June 2002 (pre-AMSR-E), 19 June 2002-30 June 2005 (early AMSR-E), 1 July 200530 June 2008 (middle AMSR-E), 1 July 2008-3 October 2011 (late AMSR-E), and 4 October 2011-31 December 2014 (post-AMSR-E; Table 1). The pre-AMSR-E era relied heavily on the TRMM microwave imager (TMI) passive observations and SCAT active retrievals that operated until 2006. In fact, the climatology of the passive dataset during this period was rescaled based on TMI data and likewise the same was true of AMSR-E during eras 2-4. During the early AMSR-E era, passive observations from the WindSat satellite became available online (Gaiser, 2004). The middle AMSR-E era was a time of transition in terms of active observations as the SCAT satellite was replaced by ASCAT. The late AMSR-E era saw the arrival of the ESA SMOS mission. After the failure of AMSR-E, SMOS observations took on a more prominent role within the CCI passive microwave framework. Also during the post-AMSR-E era, the Japanese Space Agency launched AMSR2 (Wentz et al., 2014), which is considered the replacement for the long-lasting AMSR-E mission.

\subsection{In situ soil moisture}

Direct in situ comparisons were made between RZSM estimates with in situ data from the International Soil Moisture Network (ISMN; Dorigo et al., 2011). The ISMN provides access to a host of meteorological and soil moisture data (at many depths). In this study, we selected soil moisture at two depths. Surface soil $(0-10 \mathrm{~cm})$ and RZSM $(20-25 \mathrm{~cm})$ moisture were compared to assess the performance of the exponential filter method. In this study, we focused on four networks within CONUS that have been examined in previous studies. Al Bitar et al. (2012) conducted an extensive evaluation of SMOS data using two networks; we utilized the Soil Climate Analysis Network (SCAN; $20.32 \mathrm{~cm}$ ) and SNOw- pack TELemetry (SNOTEL; $20.32 \mathrm{~cm}$ ). Additionally, we obtained soil moisture observations from two other CONUS networks: the US Department of Energy Atmospheric Radiation Measurement (ARM; $25 \mathrm{~cm}$ ) program (Jackson et al., 1999) and the US Climate Reference Network (USCRN; $20 \mathrm{~cm}$; Bell et al., 2013). Complete ARM observations only existed from eras 1 to 4 , and USCRN data were available for only era 5 (Table 1). In situ values were aggregated to a daily time step (based on UTC time) that matched the surface satellite-based soil moisture product described below. Figures 1 and 2 show the location of the stations selected across the five eras.

The ARM network used the Campbell Scientific 229-L heat dissipation matric potential sensor to estimate soil moisture (Reece, 1996). Calibration of this method was based on comparison of matric potential with soil water release curves (Klute, 1986). Conversely, the SCAN, SNOTEL, and USCRN networks all used a Stevens Water Hydra Probe (Schaefer et al., 2007; Bell et al., 2013). Seyfried et al. (2005) described the calibration approach and how the dielectric measurements from the Hydra Probe sensor were converted into volumetric soil moisture measurements.

\subsection{Surface satellite-based soil moisture}

This study was supported by four surface $(5 \mathrm{~cm})$ soil moisture products, three of which came from the CCI program. We used the CCI-passive, CCI-active, and CCI-combined products (version 2.2). The harmonization process involved in the creation of these products was described by Liu et al. (2012) and these datasets are available online (http://www. esa-soilmoisture-cci.org/node/145). In addition, we also utilized stand-alone data from the AMSR-E mission during eras 2-4. In this study, we acquired the version produced by the Land Surface Parameter Model (LPRM; Owe et al., 2008; ftp://hydrol.sci.gsfc.nasa.gov/data/s4pa/WAOB). All of these satellite soil moisture products were produced at a daily time step with a $0.25^{\circ}$ spatial resolution.

\subsection{Other datasets}

Several other datasets were used in an ancillary role. Air temperature and precipitation data were obtained from the $\mathrm{Pa}$ rameter elevation Regression on Independent Slopes Model (PRISM; Daly et al., 1994) from grid cells (4 km spatial resolution) co-located with examined in situ sites (PRISM Climate Group 2015). These data were used to screen dates below freezing and with significant precipitation data, as suggested by Dorigo et al. (2011), to enhance quality control.

In addition, normalized difference vegetation index (NDVI) values (Tucker, 1979) were used to help constrain the only unknown in the exponential filter (the characteristic time length) and were derived from Moderate Resolution Imagining Spectroradiometer (MODIS) data. The version of MODIS (MOD13Q1) used near-infrared reflectances 
(a)
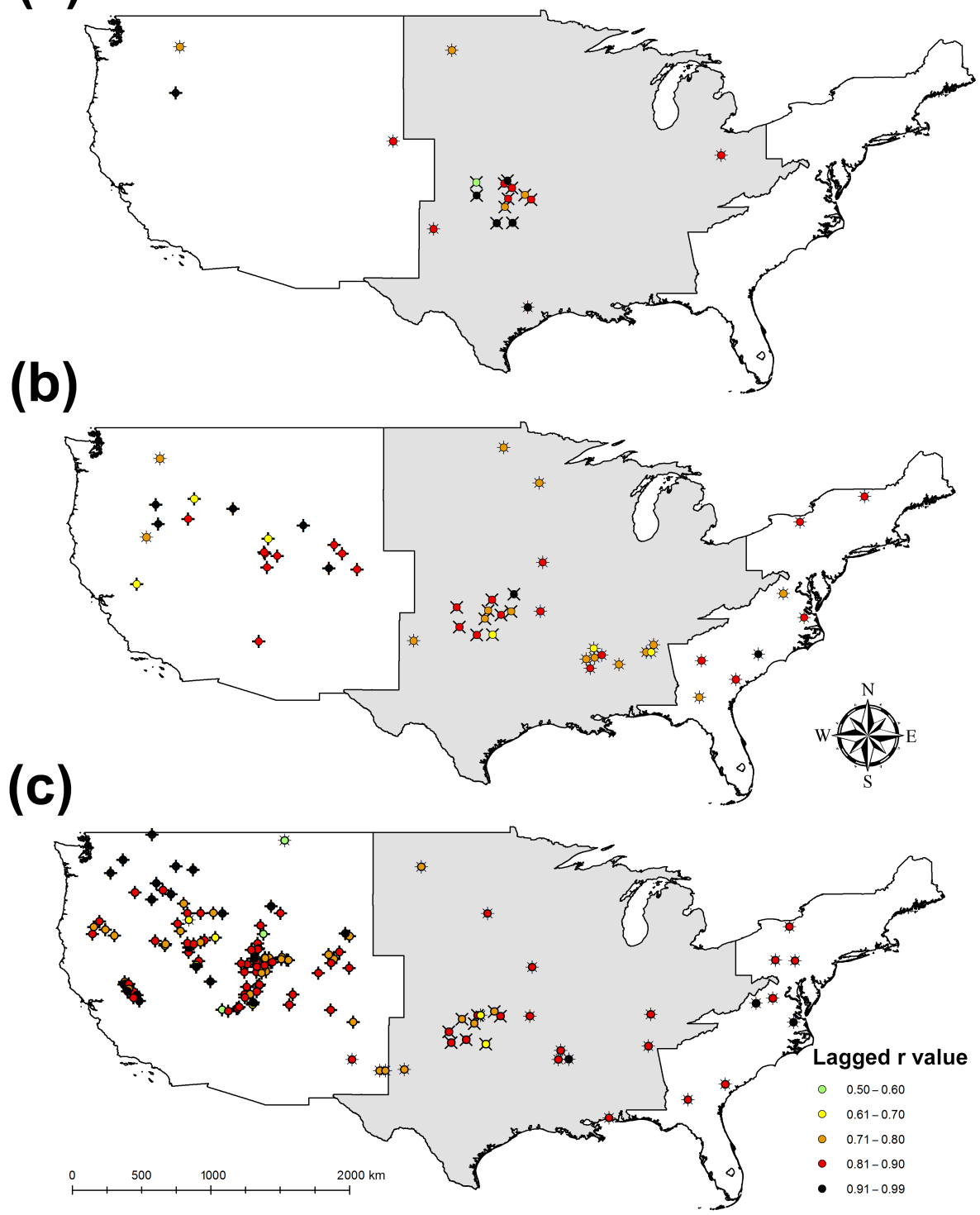

Figure 1. Locality map of examined in situ stations (ARM: X; SCAN: $*$; SNOTEL: + ) with (a) era 1, (b) era 2, and (c) era 3. The gray area represents the central CONUS, whereas white indicates the eastern and western regions of CONUS.

that were atmospherically corrected to mask water, clouds, aerosols, and cloud shadows. Datasets were provided in a sinusoidal grid with a $250 \mathrm{~m}$ resolution, and an average of nine pixels around each in situ station were used to calculate a global average NDVI for each era.

\section{Methods}

\subsection{Initial station filtering}

To ensure selection of the highest-quality in situ stations, we applied two criteria in our initial station selection. The first criterion involved the amount of missing data within a candidate station. Sites that had an excessive number of missing data, a total of over 20 days per year, were rejected. A second criterion related to a fundamental assumption of the exponential filter method, which is that there is a hydrologic connection between the surface and root-zone horizons. One would expect that deeper within the profile there would be a greater lag in response. Therefore, a lagged $r$ value between surface measurements (generally made at $5 \mathrm{~cm}$ ) and root-zone data from 20 to $25 \mathrm{~cm}$ depth was made. Root-zone lag was calculated between 1 and 40 days, and the day with the highest lagged $r$ value was selected. Stations whose maximum 

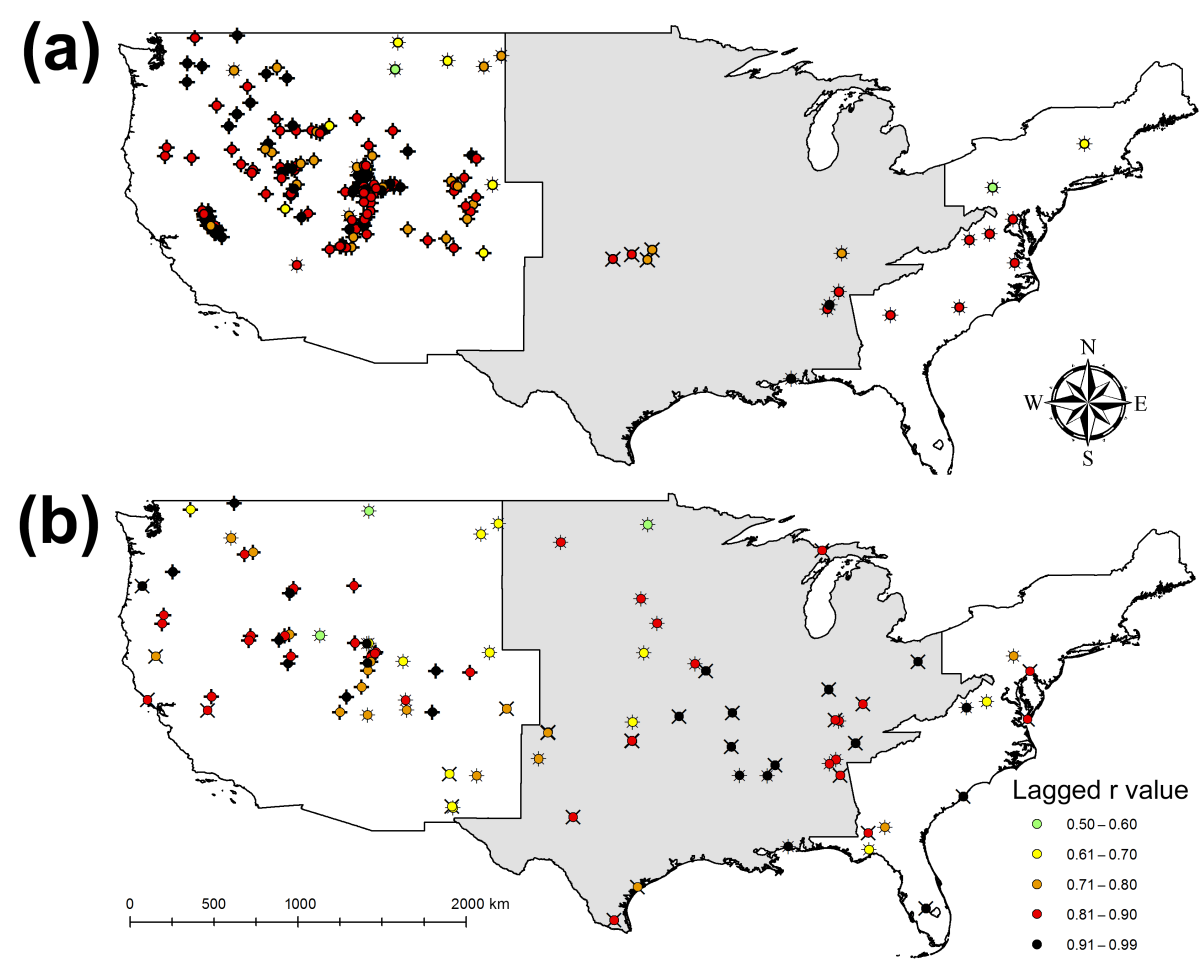

Figure 2. Locality map of examined in situ stations (ARM: X; SCAN: $*$; SNOTEL: +) with (a) era 4 and (b) era 5. During era 5, X represents USCRN instead of ARM stations. The gray area represents the central CONUS, whereas white indicates the eastern and western regions of CONUS.

lagged $r$ value fell below 0.5 were rejected. Qiu et al. (2014) used a similar selection criterion in their study.

\subsection{Exponential filter}

Wagner et al. (1999) originally developed the exponential filter and Albergel et al. (2008) refined this approach with a more robust recursive version of this method. This version provided an estimate of a soil wetness index (SWI) within the root zone. This index standardized RZSM based on the total range of values recorded by the in situ dataset. The recursive formulation provided a predictor of RZSM at time $\left(t_{n}\right)$, which in this study was given in days and was derived as

$\mathrm{SWI}_{m n}=\mathrm{SWI}_{m n(n-1)}+K_{n}\left[\mathrm{~ms}\left(t_{n}\right)-\mathrm{SWI}_{m n(n-1)}\right]$,

where SWI $m n(n-1)$ represented the estimated RZSM at time $t_{n-1}, \operatorname{ms}\left(t_{n}\right)$ was the surface soil moisture estimate based on either CCI products or AMSR-E retrievals, and $K_{n}$ was the gain at time $t_{n}$ determined with

$K_{n}=\frac{K_{n-1}}{K_{n-1}+e^{\frac{t_{n-t_{n-1}}}{T}}}$,

where $T$ represented the timescale of soil moisture variation in days. At the beginning of each era and after excessively large gaps in $\operatorname{ms}\left(t_{n}\right)$ data (>12 days), the filter was initialized with $\mathrm{SWI}_{m(1)}=\mathrm{ms}\left(t_{n}\right)$ and $K_{n 1}$ set to 1 . Results from a data denial experiment described below provided support for the selection of 12 days as an appropriate timescale to reset the filter. The prime advantage of the exponential filter was that the only unknown was $T$. Finally, the $\mathrm{SWI}_{m n}$ generated from the exponential filter, which ranged from 0 to 1000 , was rescaled to match the range of the in situ data (in volumetric units) allowing for comparisons between these datasets.

\subsection{Objective metrics}

Direct comparisons were made between CONUS in situ stations that represented a long time series. While it is true that soil moisture measurements exhibit a high degree of spatial variability over a wide range of spatial scales from field plot to watershed (e.g., Western et al., 2004; Wilson et al., 2004; Brocca et al., 2007), temporal variation is much more muted. Temporal stability is a concept fully rooted in soil science (Vachaud et al., 1985; Martinez-Fernandez and Ceballos, 2003). Therefore, the approach of this study was to use standard objective metrics such as lagged $r$ values to describe the relationship between (coarse-scale) root-zone soil moisture estimates based on the exponential filter and (point-scale) in situ measurements. Other temporal statistics included bias, Nash-Sutcliffe coefficients (NSs), and root mean square error (RMSE, in volumetric soil moisture). In terms of bias, re- 
sults are also evaluated based on whether the absolute bias is low (within $10 \%$ ) or high (greater than $10 \%$ ), which strongly impacts the other objective metrics. Each of these metrics has their own utility as discussed in the paper below.

\subsection{Calibration of $T_{\text {opt }}$}

Albergel et al. (2008) noted no significant correlation between soil properties and the optimal timescale of soil moisture variation $\left(T_{\mathrm{opt}}\right)$. Therefore, they constrained this parameter by optimizing $T$ based on the NS metric, an approach also applied by Ford et al. (2014). However, Albergel et al. (2008) also noted a weak relationship between $T$ with climate. Specifically, a linkage between increased temperatures and hence soil evaporation (not transpiration). A lower $T_{\mathrm{opt}}$ was representative of a faster response of SWI present in areas with a higher evaporational demand. This conjecture was consistent with a relationship developed by Qiu et al. (2014) using mean NDVI values at in situ sites.

In this study, we used two approaches to determine $T_{\text {opt }}$. The first method optimized $T_{\text {opt }}$ at a time in which the RMSE is minimized. This was essentially the same approach as finding a maximum NS value. RMSE was calculated between 1 and 68 days at a 1-day increment. Sites that converged on the upper 68-day bound were rejected. Qiu et al. (2014) used a similar upper bound as a means of selecting SCAN sites for their study.

The second approach used the NDVI formulation from Qiu et al. (2014) to calculate $T_{\text {opt }}$. This relationship is given as

$T_{\mathrm{opt}}=[-75.263 \times \mathrm{NDVI}]+68.171$.

\subsection{In situ station filtering and data denial experiment}

To ensure that the exponential filter was effective in producing a RZSM estimate, the $\mathrm{ms}\left(t_{n}\right)$ term was set based on surface $(5 \mathrm{~cm})$ in situ data instead of satellite data. Normally, grid-based satellite surface moisture estimates are used to drive the exponential filter. However, to establish a filter based on the quality of in situ data, an initial estimate of RZSM is determined based on surface in situ data at the $5 \mathrm{~cm}$ level. Initial RZSM estimates with a NS value less than 0.50 , which is a common threshold for defining a satisfactory match between in situ and simulated hydrologic data (Moriasi et al., 2007), were rejected. This filter removed many of the poor-performing outliers ( $\mathrm{NS}<-1.00$ ) from consideration. Table 2 describes the issues with the remaining poorperforming outliers that lingered after this in situ based filtering approach.

Use of surface $(5 \mathrm{~cm})$ in situ data also supported a data denial experiment that gauged how the filter's performance was impacted by gaps in the $\mathrm{ms}\left(t_{n}\right)$ time series. This experiment focused on the SCAN network during era 3 (2005-2008; Table 1). Time series were altered to include only data at 2-, 5-, $8-$, and 11-day intervals. This experiment was based on the
Table 2. Number of poor-performing (NS < 1.00) outliers for all four satellite products.

\begin{tabular}{lrrrr}
\hline & ARM & SCAN & SNOTEL & USCRN \\
\hline RMSE optimization & & & & \\
\hline In situ data & 17 & 3 & 15 & 1 \\
Insufficient SWI & 0 & 1 & 14 & 0 \\
Lack of range & 0 & 11 & 0 & 3 \\
Timing issues & 0 & 0 & 9 & 0 \\
\hline NDVI approach & & & & \\
\hline In situ data & 22 & 16 & 32 & 5 \\
Insufficient SWI & 0 & 3 & 44 & 0 \\
Lack of range & 0 & 17 & 15 & 8 \\
Timing issues & 0 & 6 & 5 & 3 \\
\hline
\end{tabular}

32 out of 42 sites that had in situ based NS in excess of 0.50 , i.e., the sites that survived this filtering process. Both surface $(5 \mathrm{~cm})$ in situ and satellite (AMSR-E) data were used in this experiment.

\subsection{Spurious data filtering}

Before calculation of SWI values for all four satellite products at each in situ station, a series of filters were applied to remove any spurious results following the quality control guidelines articulated by Dorigo et al. (2013). Surface temperature and precipitation data from co-located PRISM grid cells flagged problematic dates within the time series of each dataset. Satellite retrieval from days in which the minimum air temperature was less than $0{ }^{\circ} \mathrm{C}$ were removed from the SWI dataset. Satellite soil moisture retrievals were particularly fraught with difficulty under freezing conditions (Dorigo et al., 2011). Likewise, precipitation can be problematic and days with greater than $1 \mathrm{mmday}^{-1}$ were excised following the guidance of Dorigo et al. (2013). Three additional flags related to the quality of the in situ data were applied. Days with values in excess of the porosity reported by the ISMN were expunged from the rescaled SWI dataset. Likewise, days that recorded the same value (plateaus) or zero were deemed spurious and removed. The final filtered rescaled SWI dataset consisted of less than 100 days; this dataset was rejected following the guidance of Dorigo et al. (2013). Finally, SWI based estimates in which $\mathrm{NS}<-1.00$ were rejected as outliers. A detailed discussion of these outliers is given below.

\section{Results}

Figure 3 shows the results of the data denial experiment in which both in situ and satellite data (AMSR-E) were used at the surface. Note a baseline performance for in situ dataset has average NS values close to 0.7 , which was almost iden- 
Table 3. Average lagged $r$ values and $T_{\text {opt }}$ between SWI based and in situ soil moisture at the $25 \mathrm{~cm}$ depth for the ARM network. Standard derivation is indicated in parentheses. The $n$ value represents the number of observations.

\begin{tabular}{|c|c|c|c|c|c|c|c|c|c|c|c|c|}
\hline \multirow[b]{2}{*}{ Era } & \multicolumn{3}{|c|}{ AMSR-E } & \multicolumn{3}{|c|}{ CCI-combined } & \multicolumn{3}{|c|}{ CCI-passive } & \multicolumn{3}{|c|}{ CCI-active } \\
\hline & $n$ & $r$ value & $T_{\mathrm{opt}}$ & $n$ & $r$ value & $T_{\mathrm{opt}}$ & $n$ & $r$ value & $T_{\mathrm{opt}}$ & $n$ & $r$ value & $T_{\mathrm{opt}}$ \\
\hline \multicolumn{13}{|c|}{ Optimization approach - low bias } \\
\hline 1 & - & - & - & 14 & $0.471(0.249)$ & $30(19)$ & 4 & $0.614(0.131)$ & $25(29)$ & 9 & $0.450(0.193)$ & $26(13)$ \\
\hline 2 & 9 & $0.587(0.080)$ & (1) & 10 & $0.491(0.136)$ & $9 \quad(4)$ & 10 & $0.554(0.103)$ & $7 \quad(6)$ & 11 & $0.493(0.153)$ & 17 (7) \\
\hline 3 & 12 & $0.589(0.148)$ & $7 \quad(3)$ & 12 & $0.520(0.156)$ & $12(10)$ & 12 & $0.615(0.165)$ & $8 \quad(4)$ & 12 & $0.460(0.165)$ & $13(10)$ \\
\hline 4 & 4 & $0.666(0.053)$ & $32(10)$ & 3 & $0.707(0.081)$ & 10 & 2 & $0.649(0.011)$ & $12(1)$ & 1 & 0.823 & 5 \\
\hline \multicolumn{13}{|c|}{ NDVI approach - low bias } \\
\hline 1 & - & - & - & 17 & $0.439(0.241)$ & $36 \quad(3)$ & 9 & $0.480(0.171)$ & $36(2)$ & 12 & $0.414(0.172)$ & 36 (4) \\
\hline 2 & 7 & $0.622(0.156)$ & $35 \quad(3)$ & 11 & $0.567(0.172)$ & $34(4)$ & 9 & $0.642(0.132)$ & $34(4)$ & 13 & $0.484(0.154)$ & 32 (3) \\
\hline 3 & 13 & $0.559(0.204)$ & 34 (2) & 12 & $0.437(0.179)$ & $35 \quad(3)$ & 10 & $0.645(0.137)$ & $34(3)$ & 12 & $0.341(0.197)$ & 34 (3) \\
\hline 4 & 5 & $0.666(0.053)$ & $32(6)$ & 3 & $0.704(0.004)$ & $34(2)$ & 3 & $0.665(0.542)$ & $34 \quad(2$ & 7 & $0.323(0.184)$ & 32 (3) \\
\hline
\end{tabular}

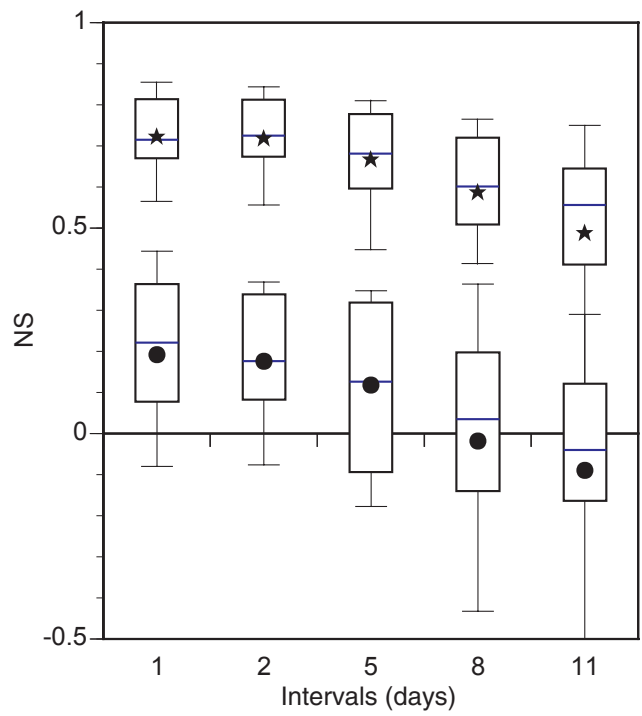

Figure 3. Box plot of the data denial experiment from the SCAN network during era 3 (2005-2008). Results for day 1 represent baseline data for the exponential filter driven by surface soil moisture data (in situ data: $\star$; low absolute bias RMSE-optimized AMSRE: •). Other time series were altered to include only data at 2-, 5-, 8-, and 11-day intervals.

tical to the results based on in situ surface soil moisture datasets in which every other day was withheld. Even in datasets with every four out of five dates withheld there was only a slight drop in performance. This result underscored the ability of the exponential filter to effectively cope with datasets that have significant gaps. Average NS values fell to 0.5 only when over $90 \%$ of the surface soil moisture dataset was withheld and measurements from only every 11th day were used. The data denial experiment using AMSR-E data to drive the filter yielded a similar drop-off in performance as the number of withheld days increased.
Figures 1 and 2 show lagged $r$ values between in situ surface $(5 \mathrm{~cm})$ and RZSM $(20-30 \mathrm{~cm})$ during the five eras. ARM sites clustered in Oklahoma and Kansas had higher lagged $r$ values during era 1 (network average $r=0.864$ ) and a drop in this metric during eras 2 to 4 (network average $r=0.793$ 0.796). SCAN sites exhibited correlation coefficients that varied spatially. In general, better performances were noted from eastern (network average $r=0.751-0.872$ ) and central sites (network average $r=0.812-0.874$ ). Western sites had slightly lower $r$ values (network average $r=0.699-0.770$ ). Notable outliers were present for the stations in Montana during eras 4 and 5 (Fig. 2) that could account partly for the poorer performance noted during these eras. SNOTEL stations were concentrated in the western CONUS and had consistently high correlation coefficients (network average $r=0.828-0.865)$. Finally, the USCRN sites examined during era 5 (Table 1) generally had better $r$ values in eastern and central CONUS (network average $r=0.846-0.882$ ) as opposed to the west (network average $r=0.768$ ).

The remainder of this section focuses on the results from the exponential filter driven by the four satellite products. The $T_{\text {opt }}$ and lagged $r$ values discussed are based on results that have a low absolute bias $( \pm 10 \%)$. Note that the proportion of sites that recorded low bias varies between networks (data not shown). Most ARM stations were characterized by having low bias (76-100\%), whereas SNOTEL sites had the lowest number of sites with a low bias (32-45\%). SCAN (53-60\%) and USCRN (60-66\%) had an intermediate number of sites with a low bias. The subsequent results focused only on the low bias stations.

As might be expected, the $T_{\mathrm{opt}}$ values from the NDVI approach had a much more limited range of values compared with $T_{\mathrm{opt}}$ values derived using the optimization approach (Tables 3-6). From the ARM network, average $T_{\text {opt }}$ based on the NDVI approach ranged from 32 to 36 days, whereas optimization produced much greater variation (4-32 days; Table 3). At SCAN, the NDVI approach yielded a broader 
Table 4. Average lagged $r$ values and $T_{\text {opt }}$ between SWI based on optimization and in situ soil moisture at the $20.32 \mathrm{~cm}$ depth for the SCAN network (Figs. 1 and 2). Standard derivation is indicated in parentheses. The $n$ value represents the number of observations.

\begin{tabular}{|c|c|c|c|c|c|c|c|c|c|c|c|c|}
\hline \multirow[b]{2}{*}{ Era } & \multicolumn{3}{|c|}{ AMSR-E } & \multicolumn{3}{|c|}{ CCI-combined } & \multicolumn{3}{|c|}{ CCI-passive } & \multicolumn{3}{|c|}{ CCI-active } \\
\hline & $n$ & $r$ value & $T_{\mathrm{opt}}$ & $n$ & $r$ value & $T_{\mathrm{opt}}$ & $n$ & $r$ value & $T_{\mathrm{opt}}$ & $n$ & $r$ value & $T_{\mathrm{opt}}$ \\
\hline \multicolumn{13}{|c|}{ Optimization approach - low bias } \\
\hline 1 & - & - & - & 1 & 0.817 & 19 & 1 & 0.691 & 1 & 3 & $0.458(0.323)$ & $22(10)$ \\
\hline 2 & 4 & $0.691(0.157)$ & 39 (19) & 7 & $0.598(0.157)$ & $27(16)$ & 2 & $0.661(0.007)$ & $16(9)$ & 7 & $0.519(0.147)$ & $15(6)$ \\
\hline 3 & 17 & $0.596(0.129)$ & $10 \quad(7)$ & 19 & $0.556(0.164)$ & $14(13)$ & 16 & $0.556(0.184)$ & $9 \quad(5)$ & 17 & $0.521(0.140)$ & $17(17)$ \\
\hline 4 & 14 & $0.697(0.096)$ & $15(14)$ & 16 & $0.698(0.155)$ & $19(15)$ & 10 & $0.720(0.176)$ & $15(12)$ & 16 & $0.642(0.226)$ & $17(16)$ \\
\hline 5 & - & - & - & 17 & $0.572(0.183)$ & $16(15)$ & 11 & $0.472(0.192)$ & $21(14)$ & 15 & $0.589(0.195)$ & $14(14)$ \\
\hline \multicolumn{13}{|c|}{ NDVI approach - low bias } \\
\hline 1 & - & - & - & 2 & $0.678(0.199)$ & $32(6)$ & 2 & $0.747(0.096)$ & 49 & 4 & $0.463(0.282)$ & $40(10)$ \\
\hline 2 & 6 & $0.554(0.198)$ & $34(16)$ & 7 & $0.541(0.179)$ & $30(12)$ & 1 & 0.330 & 20 & 10 & $0.505(0.171)$ & 28 (7) \\
\hline 3 & 14 & $0.596(0.111)$ & $31(10)$ & 15 & $0.480(0.193)$ & $34(11)$ & 15 & $0.613(0.095)$ & $36(11)$ & 15 & $0.471(0.187)$ & $31(10)$ \\
\hline 4 & 16 & $0.573(0.242)$ & $37(15)$ & 20 & $0.585(0.223)$ & $39(15)$ & 14 & $0.615(0.238)$ & $39(15)$ & 20 & $0.608(0.226)$ & $40(15)$ \\
\hline 5 & - & - & - & 19 & $0.518(0.220)$ & $39(13)$ & 15 & $0.428(0.238)$ & $46(11)$ & 26 & $0.469(0.237)$ & $41(13)$ \\
\hline
\end{tabular}

Table 5. Average lagged $r$ values and $T_{\text {opt }}$ between SWI based on optimization and in situ soil moisture at the $20.32 \mathrm{~cm}$ depth for the SNOTEL network. Standard derivation is indicated in parentheses. The $n$ value represents the number of observations.

\begin{tabular}{|c|c|c|c|c|c|c|c|c|c|c|c|c|}
\hline \multirow[b]{2}{*}{ Era } & \multicolumn{3}{|c|}{ AMSR-E } & \multicolumn{3}{|c|}{ CCI-combined } & \multicolumn{3}{|c|}{ CCI-passive } & \multicolumn{3}{|c|}{ CCI-active } \\
\hline & $n$ & $r$ value & $T_{\mathrm{opt}}$ & $n$ & $r$ value & $T_{\mathrm{opt}}$ & $n$ & $r$ value & $T_{\mathrm{opt}}$ & $n$ & $r$ value & $T_{\mathrm{opt}}$ \\
\hline \multicolumn{13}{|c|}{ Optimization approach - low bias } \\
\hline 2 & 5 & $0.572(0.311)$ & $17(15)$ & 2 & $0.600(0.0$ & 10 (1) & 2 & $0.750(0$ & $14 \quad(7)$ & 3 & $0.509(0$ & $36(13)$ \\
\hline 3 & 39 & $0.463(0.264)$ & $20(15)$ & 17 & $0.513(0.290)$ & $27(18)$ & 30 & $0.461(0.293)$ & $25(20)$ & 30 & $0.370(0.317)$ & $29(11)$ \\
\hline 4 & 63 & $0.508(0.299)$ & 18 (14) & 32 & $0.491(0.353)$ & $20(16)$ & 55 & $0.522(0.302)$ & $18(11)$ & 32 & $0.522(0.379)$ & $22(18)$ \\
\hline 5 & - & - & - & 5 & $0.527(0.189)$ & $25(13)$ & 12 & $0.412(0.252)$ & $26(17)$ & 8 & $0.534(0.319)$ & $27(21)$ \\
\hline \multicolumn{13}{|c|}{ NDVI approach - low bias } \\
\hline 2 & 2 & $0.678(0.197)$ & $44(13)$ & 1 & 0.438 & 49 & 4 & $0.584(0$ & $45 \quad(8)$ & 4 & $0.444(0$ & 44 (7) \\
\hline 3 & 44 & $0.367(0.374)$ & $44 \quad(6)$ & 28 & $0.313(0.395)$ & $44 \quad(7)$ & 43 & $0.334(0.386)$ & $44 \quad(6)$ & 45 & $0.327(0.337)$ & $44 \quad(5)$ \\
\hline 4 & 71 & $0.425(0.367)$ & $43 \quad(6)$ & 33 & $0.385(0.491)$ & $43 \quad(7)$ & 61 & $0.451(0.341)$ & $44 \quad(7)$ & 41 & $0.228(0.529)$ & $44 \quad(6)$ \\
\hline 5 & - & - & - & 11 & $0.425(0.216)$ & $44 \quad(7)$ & 9 & $0.357(0.318)$ & $43 \quad(5)$ & 10 & $0.590(0.268)$ & $42 \quad(6)$ \\
\hline
\end{tabular}

range of average era $T_{\text {opt }}$ (28-46 days; Table 3 ). However, again, optimization produced more variable $T_{\text {opt }}$ values (939 days; Table 4). A similar pattern was noted at SNOTEL sites. The NDVI approach yielded higher network average era $T_{\text {opt }}$ values (42-45 days) vs. the more variable and lower results from the optimization method (17-36 days; Table 5). Finally, USCRN sites from era 5 (Table 1) exhibited a broad range of values for both approaches (NDVI of 30-55 days; optimization of 9-28 days; Table 6).

Tables 3-6 show results from the direct correlation between in situ RZSM- and SWI-based estimates generated from the four satellite products. Network average values are excluded in this discussion if there were less than three measurements within an era for a network. Generally, but not always, the optimization approach yielded higher lagged $r$ values than NDVI. Interestingly, in the ARM network, in 5 out of 14 instances, the NDVI approach yielded network aver- age $r$ values that were greater than those obtained from the optimization method (Table 3). ARM sites from the central Great Plains had network average $r$ values based on optimization that ranged from 0.450 to 0.707 across eras $1-4$ (Table 1), whereas the NDVI approach yielded a lower and broader variation in $r$ values (0.323-0.704; Table 3).

For SCAN sites, comparisons were made only for eras 2 5 (Tables 1, 4). Era 1 was excluded in this comparison due to limited data availability during this period. Network average $r$ values based on optimization (0.458-0.720; Table 3) generally outperformed those based on the NDVI approach (0.428-0.615; Table 4). Additionally, when examined from a geographic prospective, western CONUS sites had slightly higher $r$ values based on optimization (0.477-0.823) than those from either the eastern $(0.332-0.777)$ or central regions (0.492-0.717). 
Table 6. Average lagged $r$ values $T_{\mathrm{Opt}}$ between SWI based on optimization and in situ soil moisture at the $20 \mathrm{~cm}$ depth for the USCRN network during era 5. Standard derivation is indicated in parentheses. Sites are divided by region (east, central, west) as indicated in Fig. 2. The $n$ value represents the number of observations.

\begin{tabular}{|c|c|c|c|c|c|c|c|c|c|}
\hline \multirow[b]{2}{*}{ Region } & \multicolumn{3}{|c|}{ CCI-combined } & \multicolumn{3}{|c|}{ CCI-passive } & \multicolumn{3}{|c|}{ CCI-active } \\
\hline & $n$ & $r$ value & $T_{\mathrm{opt}}$ & $n$ & $r$ value & $T_{\mathrm{opt}}$ & $n$ & $r$ value & $T_{\mathrm{opt}}$ \\
\hline \multicolumn{10}{|c|}{ Optimization approach - low bias } \\
\hline East & 1 & 0.105 & 4 & - & - & - & 1 & 0.486 & 15 \\
\hline Central & 13 & $0.594(0.185)$ & (8) & 6 & $0.707(0.086)$ & 17 (19) & 11 & $0.607(0.126)$ & $6 \quad(3)$ \\
\hline West & 1 & 0.857 & 11 & 4 & $0.406(0.125)$ & $28(21)$ & 3 & $0.540(0.389)$ & 9 (1) \\
\hline \multicolumn{10}{|c|}{ NDVI approach - low bias } \\
\hline East & 2 & $0.388(0.122)$ & 1 & 1 & 0.071 & 25 & 2 & $0.410(0.133)$ & 21 \\
\hline Central & 12 & $0.521(0.231)$ & $30(10)$ & 7 & $0.605(0.194)$ & 35 (9) & 7 & $0.534(0.176)$ & $25(7)$ \\
\hline West & 3 & $0.209(0.068)$ & $36(20)$ & 4 & $0.342(0.128)$ & $45(20)$ & 3 & $0.087(0.122)$ & $55(5)$ \\
\hline
\end{tabular}

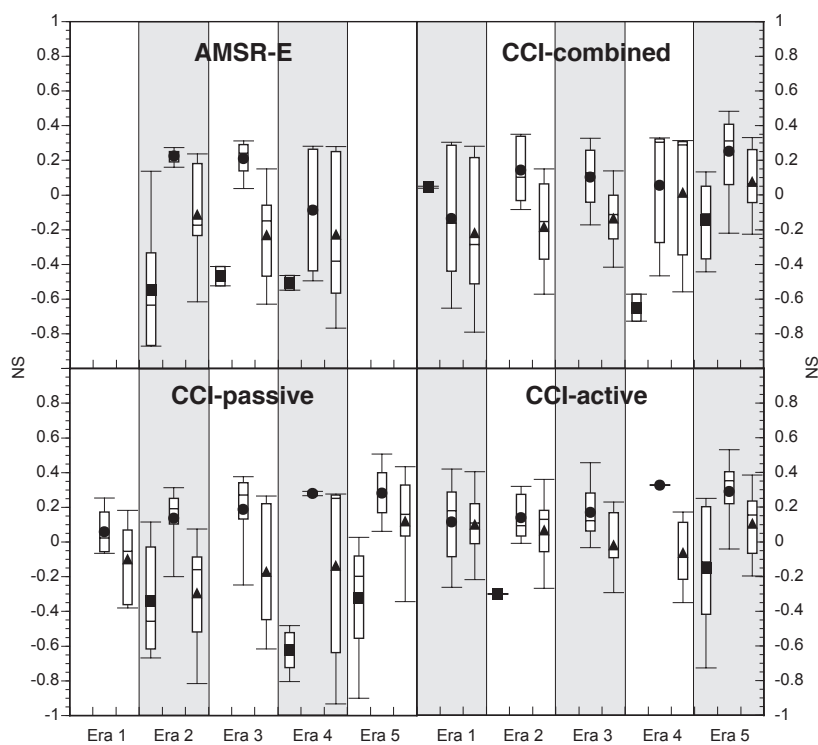

Figure 4. Box plots that depict the NS metric for the ARM (eras 14) and USCRN (era 5) networks. Results for high absolute bias RMSE-optimized datasets are squares, low absolute bias RMSEoptimized datasets are circles, and low absolute bias NDVI datasets are triangles.

SNOTEL stations from the intermountain west showed the greatest variability. Some sites recorded $r$ values below 0 , but there were also quite a few sites with high correlation coefficients $(>0.75)$. However, in general, network average $r$ values were lower in SNOTEL (optimization of 0.370-0.572; NDVI of 0.228-0.590) than at SCAN western sites (Table 5). Finally, the data from USCRN sites during era 5 (Table 1) had higher network average $r$ values in central sites vs. the western CONUS (Table 6).

NS values across the five eras were depicted in Figs. 4-6. Stations with low absolute bias $( \pm 10 \%)$ consistently outper-

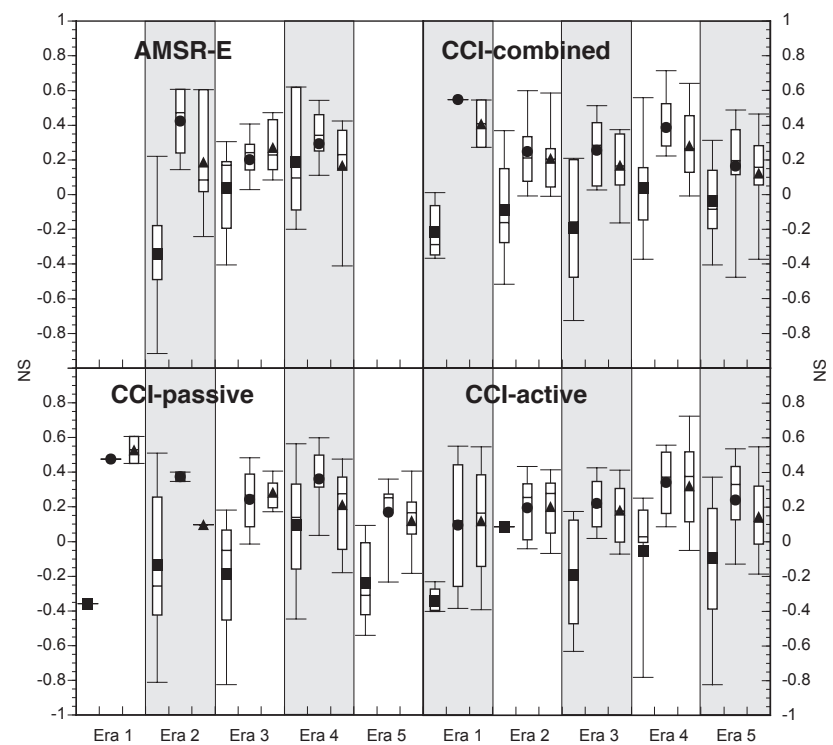

Figure 5. Box plots depicting the NS metric for the SCAN network. Symbols are the same as in Fig. 4.

formed stations with high bias within all networks and during all eras. This was true for both the optimization and NDVI (data not shown) approaches to constraining $T$. Not surprisingly, the optimization approach generally outperformed the NDVI method. Also, the four satellite products had quite consistent results and did not exhibit any clear temporal trends. All NS and RMSE network averages described below were based on the optimization approach to constraining $T$ and had a low absolute bias. Figure 4 showed NS results from the ARM and USCRN networks. Network average NS values for ARM ranged from -0.1 to 0.3 , similar to the results from the USCRN network (0.2-0.3). Network average NS values from the SCAN and SNOTEL networks were shown in Figs. 5 and 6, which were slightly higher (0.1-0.5). 


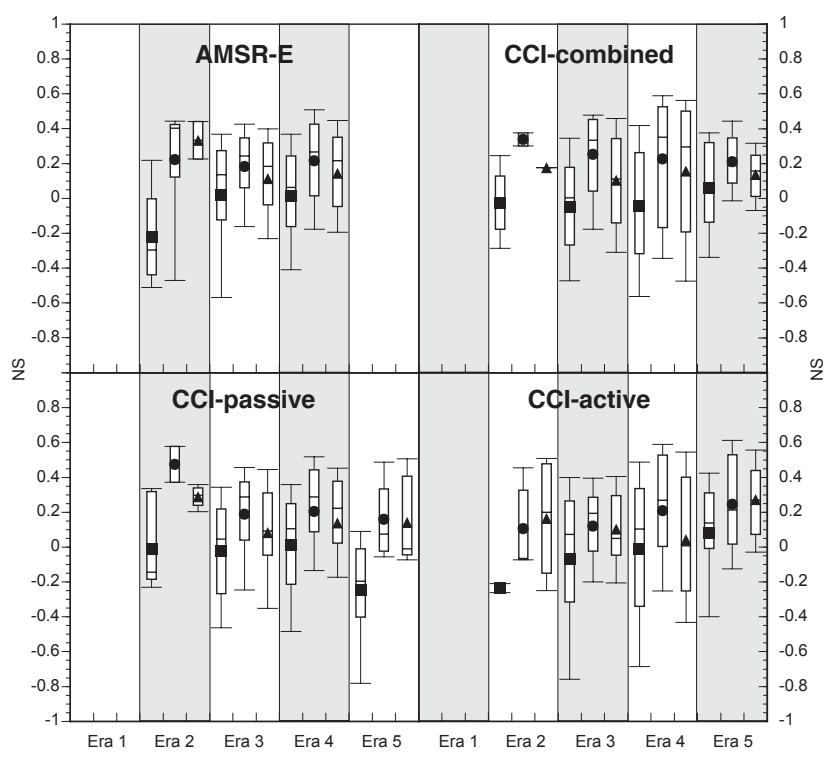

Figure 6. Box plots depicting the NS metric for the SNOTEL network. Symbols are the same as in Fig. 4.

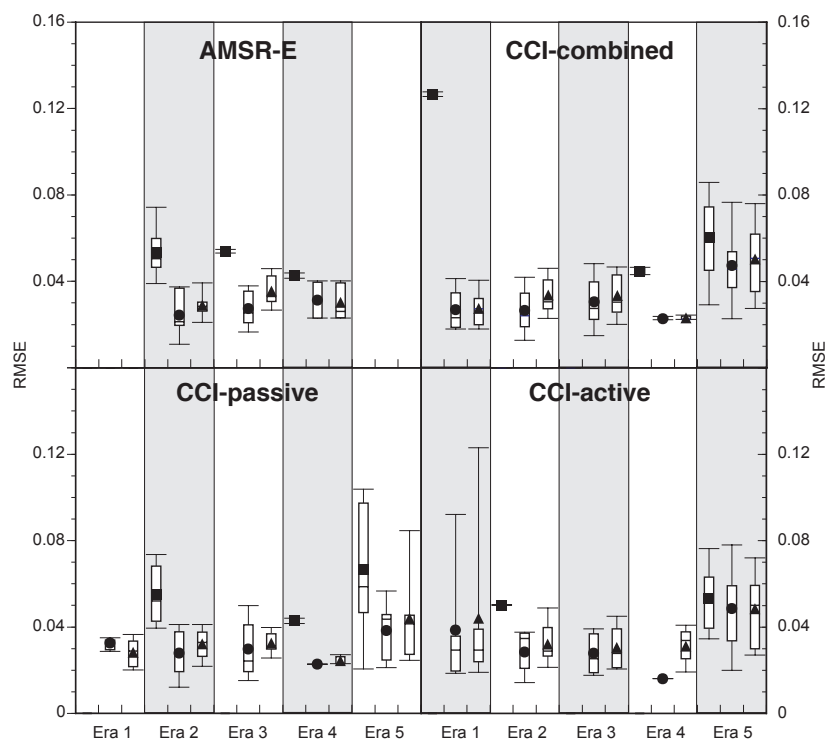

Figure 7. Box plots depicting the RMSE metric for the ARM (eras 1-4) and USCRN (era 5) networks. Symbols are the same as in Fig. 4.

Figures 7-9 depicted RMSE values again across the five eras (Table 1). In many respects, RMSE mirrors NS as a performance metric. Like NS stations, RMSE values with a low absolute bias outperformed those with high bias. However, the difference between low and high bias datasets was generally not as pronounced for the RMSE metric as it was for NS. However, like with NS, RMSE results showed no discernable temporal trends. RMSE values from the ARM and USCRN networks were illustrated in Fig. 7. Network average

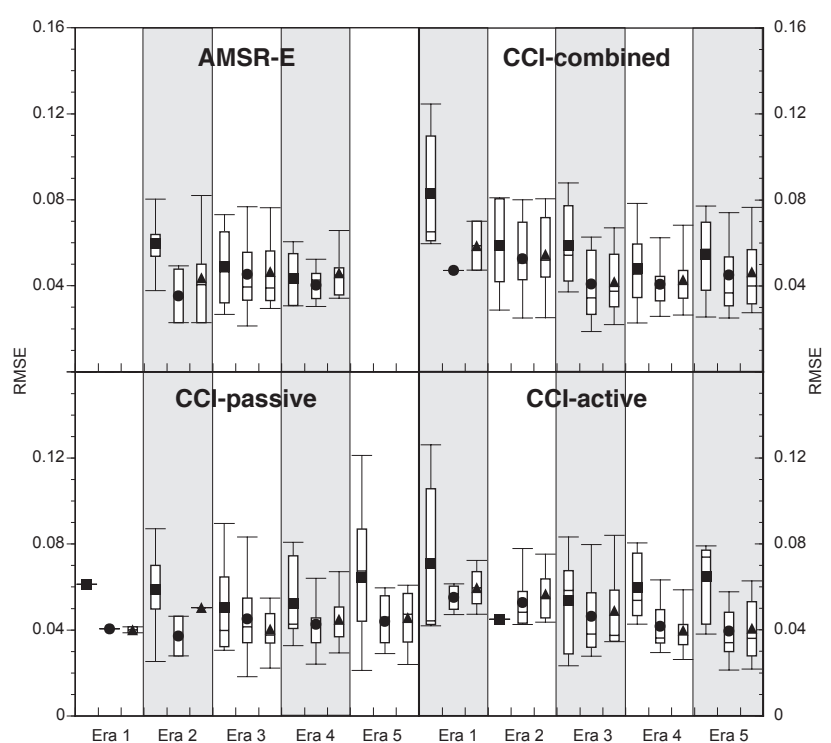

Figure 8. Box plots depicting the RMSE metric for the SCAN network. Symbols are the same as in Fig. 4.

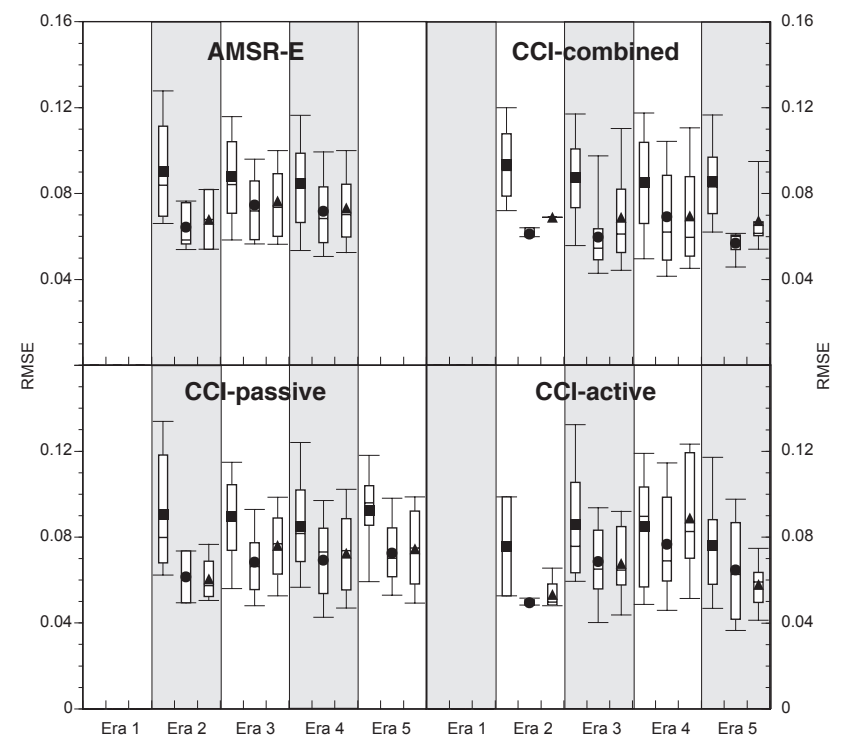

Figure 9. Box plots depicting the RMSE metric for the SNOTEL network. Symbols are the same as in Fig. 4.

RMSE values for ARM ranged from 0.02 to 0.04 and were significantly lower than values from the other networks examined in this study. USCRN network average RMSE values ranged from 0.04 to 0.05 (Fig. 7). Figure 8 illustrated results from the SCAN network, and network average RMSE values were similar to USCRN sites (0.04-0.06). Finally, SNOTEL RMSE results (Fig. 9) were higher than all other networks (0.05-0.07). 

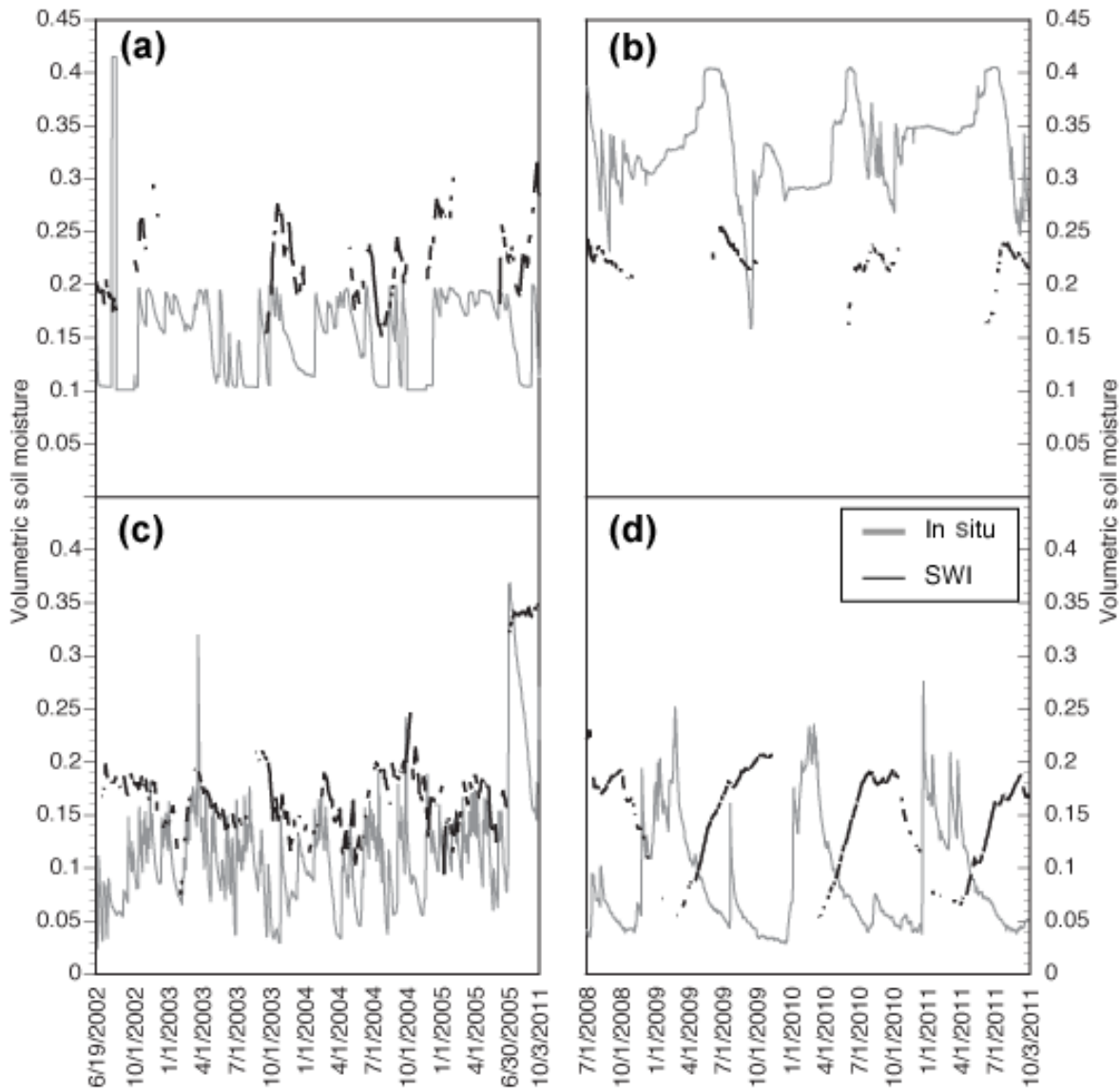

Figure 10. Selected time series associated with poorly performing (NS $<1.00)$ outliers with in situ data as solid gray and SWI estimates in dashed black. Panel (a) shows an example of problematic in situ data. Panel (b) is an example where there was insufficient SWI data. Panel (c) illustrates an SWI dataset that lacked the dynamic range present in the in situ data. Panel (d) depicts a discrepancy in timing between SWI and in situ datasets. Dates are indicated in $\mathrm{mm} / \mathrm{dd} / \mathrm{yyyy}$ format.

\section{Discussion and conclusions}

A long-standing goal of the soil remote sensing community has been to develop techniques that can observe changes in RZSM. Regrettably, the technology had not yet progressed to support a global RZSM product based only on remote sensing retrievals. The use of land surface models such as the community NOAH model (Chen et al., 1996), Global Land Data Assimilation System (GLDAS; Rodell et al., 2007), and European Centre for Medium-Range Weather Forecasts (ECMWF) reanalysis products (Uppala et al., 2005; Massari et al., 2014) have been used to fill this gap in recent years. These platforms have become popular and provide an estimate of root-zone soil moisture that has been applied to fieldscale studies (Albergel et al., 2012; Blankenship et al., 2016; Kedzior and Zawadski, 2016). In addition, another approach that has been suggested is based on thermal infrared-based remote sensing (e.g., Hain et al., 2011).

Besides ease of use, the exponential filter methodology is an attractive alternative because it leverages existing re- motely sensed soil moisture platforms. As such, this approach is not hindered by the incipit assumptions built in to every modeling platform and relies purely on observational data. Given the potential utility of the exponential filter approach, a detailed analysis of the potential errors associated with the method is in order. There are four main sources of error. Two of these errors are associated with the SWI estimate and include (1) the unsuitability of the exponential filter at a given site and (2) retrieval errors in the surface soil moisture dataset. The other two errors are not related to the actual SWI estimate but instead are errors in the independent datasets that were applied to verify the SWI estimate at the scale of the $0.25^{\circ}$ satellite grid. These errors included (3) issues with in situ datasets (Dorigo et al., 2011, 2013) and (4) non-representativeness of a point site when compared with the large $\left(0.25^{\circ}\right)$ footprint of a surface soil moisture grid used to drive the filter (Crow et al., 2012). A significant quality control measure involved driving the filter with surface in situ data instead of satellite soil moisture data. Stations that scored a NS value below 0.5 based on this approach were re- 
jected as not suitable. At these sites, perhaps the fundamental assumption of the exponential filter method that there was hydrologic equilibrium between the surface and root zone was violated. Therefore, the gross errors recorded at some sites cannot be ascribed to issues with the exponential filter, and the data denial experiment demonstrated the robustness of this method at least in certain instances (Fig. 3).

Extending this approach, we examined the quality of exponential filter results driven by surface in situ data against background conditions including soil texture, land cover, and climate zone (data not shown). In terms of soil texture, in situ sites with loamy textures has a general tendency to outperform (based on NS value) sand- or clay-dominated sites. This is not surprising given that the exponential filter generally works best when soil moisture is moderate (Ford et al., 2014). Soil textures with a low available water capacity such as sand and clay are more likely to have extreme, both dry and wet, moisture contents. In terms of land cover, the only consistent result is that in the SNOTEL network the more open rangeland settings exhibited slightly better NS values than forest-dominated areas. However, this pattern was not observed at sites from the other networks. Finally, there is no clear trend in performance of the exponential filter as a function of climate zone.

Analysis of poor-performing outliers (NS $<-1.00$ ) provided additional insights into how the exponential filter can fail at some sites (Table 2). Within the ARM network, all outliers could be attributed to in situ data issues such as spikes, breaks, anomalous high values that exceed soil porosity, anomalous low values at zero, and extended plateaus (Dorigo et al., 2013). An example of such a clearly flawed in situ dataset is shown in Fig. 10a. Within the SNOTEL network, there was more of a mix in error type (Table 3). Besides in situ data issues, another significant source of error was the limited number of days in some of the final SWI datasets. Following the guidance of Dorigo et al. (2010), SWI datasets with less than 100 days were rejected. However, based on observations in this study, significant issues of representativeness were noted when there were less than 400 days (Fig. 10b). The high altitude of many SNOTEL sites resulted in a longer freezing season during which a greater number of days were filtered out. There were some sites with in situ data issues in the SCAN network (Table 2). However, many of the outliers also were caused by either SWI values that lacked the dynamic range of the in situ dataset (Fig. 10c) or SWI values that had significant timing offsets compared with in situ RZSM observations (Fig. 10d). These issues were the result of either site non-representativeness or errors in surface soil moisture retrievals. Finally, USCRN sites exhibited a similar mix of errors as noted in the SCAN network (Table 2).

A consistent result noted in this study was the impact of bias on other performance metrics. Consistently better results for all metrics were noted (Tables 3-6; Figs. 4-9) when there was a low absolute bias (within $10 \%$ ) vs. SWI datasets that had a high absolute bias ( $>10 \%)$. Additionally, this ob- servation was observed for SWI values produced with both approaches to constrain $T$ (minimization of RMSE and the NDVI approach). The impact of bias on standard objective metrics was a focus of temporal stability analysis (Vachaud et al., 1985; Martinez-Fernandez and Ceballos, 2005). Sites with little variation in bias yielded more robust comparisons with remote sensing data (Starks et al., 2006), which is a result that was confirmed in this study across four distinct in situ soil moisture networks and satellite products.

Interestingly, the results observed in this study were more impacted by the in situ network than the surface satellite product used to drive the exponential filter. In terms of the NS metric, SCAN, SNOTEL, and USCRN outperformed ARM (Figs. 4-6). The NS metric seemed to have a greater utility in identifying outliers than the RMSE metric. This was because it ranged from 1.00 to potentially $-\infty$, unlike RMSE, which ranged in this study from only 0 to 0.14 .

Conversely, when considering the RMSE metric, ARM sites yielded superior scores compared with SCAN, SNOTEL, and USCRN (Figs. 7-9). Within the ARM network average RMSE was less than 0.04, which is the baseline value for accuracy designed for many satellite soil moisture missions (e.g., Kerr et al., 2001; Entekhabi et al., 2010). SCAN and USCRN were slightly above this guideline and were similar to RMSE values noted in previous in situ/satellite soil moisture comparisons (e.g., Brocca et al., 2010; Jackson et al., 2010, 2012; Al Bitar et al., 2012). According to the RMSE metric, SNOTEL sites performed the worst and was significantly above the 0.04 performance target.

Perhaps the most interesting result from this study was that the performance metrics in each in situ network did not vary over time. Given that almost two decades of data were examined, this finding is particularly noteworthy. Therefore, SWI estimates of RZSM produced by the exponential filter using CCI datasets can be leveraged for long-term, perhaps even multi-decadal, climate studies (Manfreda et al., 2011). Another fruitful line of future research could compare exponential filter estimates of RZSM with those generated by land surface models. With the proliferation of space-based remote sensing platforms and the continued development of in situ monitoring networks, the duration of RZSM time series will only grow. As such, the approaches outlined in this work can provide the cornerstone to support future assessments of long-term trends in RZSM, which is an essential climate variable.

Data availability. The harmonization process involved in the creation of the surface soil moisture products was described by Liu et al. (2012), and these datasets are available online (http://www. esa-soilmoisture-cci.org/node/145).

We also utilized stand-alone data from the AMSR-E mission during eras $2-4$. In this study, we acquired the version produced by the LPRM (Owe et al., 2008; https://hydro1.gesdisc.eosdis.nasa.gov/ data/WAOB/). 
Competing interests. The authors declare that they have no conflict of interest.

Acknowledgements. We acknowledge the support of the NASA Climate Indicator and Data Products for the National Climate Assessments program through award no. NNX16AH30G. The assistance of Robert Parinussa (University of New South Wales), Arturo Diaz (Texas A\&M International University), and Luis Carrasco Garza (Texas A\&M International University) is greatly appreciated.

Edited by: Erwin Zehe

Reviewed by: two anonymous referees

\section{References}

Albergel, C., Rüdiger, C., Pellarin, T., Calvet, J.-C., Fritz, N., Froissard, F., Suquia, D., Petitpa, A., Piguet, B., and Martin, E.: From near-surface to root-zone soil moisture using an exponential filter: an assessment of the method based on in-situ observations and model simulations, Hydrol. Earth Syst. Sci., 12, 1323-1337, https://doi.org/10.5194/hess-12-1323-2008, 2008.

Albergel, C., de Rosnay, P., Balsamo, G., Isaksen, L., and MunozSabater, J.: Soil moisture analyses at ECMWF: evaluation using global-based in situ observations, Remote Sens. Environ., 118, 215-226, 2012.

Al Bitar, A., Leroux, D., Kerr, Y. H., Merlin, O., Richaume, P., Sahoo, A., and Wood, E. F.: Evaluation of SMOS soil moisture products over Continental US using the SCAN/SNOTEL Network, IEEE T. Geosci. Remote, 50, 1572-1586, 2012.

Bartalis, Z., Wagner, W., Naeimi, V., Hasenauer, S., Scipai, K., Bonekmap, H., Figa, J., and Anderson, C.: Initial soil moisture retrievals from the METOP-A Advanced Scatterometer (ASCAT), Hydrol. Land Surf. Stud., 34, L02401, https://doi.org/10.1029/2007GL031088, 2007.

Bell, J. E., Palecki, M. A., Baker, C. B., Collins, W. G., Lawrimore, J. H., Leeper, R. D., Hall, M. E., Kochendorfer, J., Meyers, T. P., Wilson, T., and Diamond, H. J.: US Climate Reference Network soil moisture and temperature observations, J. Hydrometeorol., 14, 977-988, 2013.

Blankenship, C. B., Case J. L., Zavodsky, B. T., and Crosson, W. L.: Assimilation of SMOS retrievals in the Land Information System, IEEE T. Geosci. Remote, 54, 6320-6332, 2016.

Bolten, J. D. and Crow, W. T.: Improved prediction of quasi-global vegetation conditions using remotely-sensed surface soil moisture, Geophys. Res. Lett., 39, L19406, https://doi.org/10.1029/2012GL053470, 2012.

Bolten, J. D., Crow, W. T., Zhan, X., Jackson, T. J., and Reynolds, C. A.: Evaluating the utility of remotely sensed soil moisture retrievals for operational agricultural drought monitoring, IEEE J. Sel. Top. Appl., 3, 57-66, 2010.

Brocca, L., Morbidelli, R., Melone, F., and Moramarco, T.: Soil moisture spatial variability in experimental areas of central italy, J. Hydrol., 333, 356-373, 2007.

Brocca, L., Melone, F., Moramarco, T., Wagner, W., Naeimi, V., Bartalis, Z., and Hasenauer, S.: Improving runoff prediction through the assimilation of the ASCAT soil mois- ture product, Hydrol. Earth Syst. Sci., 14, 1881-1893, https://doi.org/10.5194/hess-14-1881-2010, 2010.

Chen, F., Mitchell, K., Schakke, J., Xue, Y., Pan, H., Koren, V., Duan, Y., Ek, M., and Betts, A.: Modeling of land-surface evaporation by four schemes and comparison with FIFE Observations, J. Geophys. Res., 101, 7251-7268, 1996.

Crow, W. T., Berg, A. A., Cosh, M. H., Loew, A., Mohanty, B. P., Panciera, R., de Rosnav, P., Ryu, D., and Walker, J. P.: Upscaling sparse ground -based soil moisture observations for the validation of course-resolution satellite soil moisture products, Rev. Geophys., 50, 2011RG000372, 2012.

Daly, C., Neilson, R. P., and Phillips, D. L.: A statisticaltopographic model for mapping climatological precipitation over mountainous terrain, J. Appl. Meteorol., 33, 140-158, 1994.

Dorigo, W. A., Scipal, K., Parinussa, R. M., Liu, Y. Y., Wagner, W., de Jeu, R. A. M., and Naeimi, V.: Error characterisation of global active and passive microwave soil moisture datasets, Hydrol. Earth Syst. Sci., 14, 2605-2616, https://doi.org/10.5194/hess-142605-2010, 2010

Dorigo, W. A., Wagner, W., Hohensinn, R., Hahn, S., Paulik, C., Xaver, A., Gruber, A., Drusch, M., Mecklenburg, S., van Oevelen, P., Robock, A., and Jackson, T.: The International Soil Moisture Network: a data hosting facility for global in situ soil moisture measurements, Hydrol. Earth Syst. Sci., 15, 1675-1698, https://doi.org/10.5194/hess-15-1675-2011, 2011.

Dorigo, W. A., Xavier, A., Vreugdenhill, M., Gruber, A., Hegyiová, A., Sanchis-Dufau, A. D., Zamojski, D., Cordes, C., Wagner, W., and Drusch, M.: Global automated quality control of in situ soil moisture data from the International Soil Moisture Network, Vadose Zone J., 12, vzj2012.0097, https://doi.org/10.2136/vzj2012.0097, 2013.

Entekhabi, D., Njoku, E. G., O’Neill, P. E., Kellogg, K. H., Crow, W. T., Edelstein, W.N., Entin, J. K., Goodman, S. D., Jackson, T. J., Johnson, J., Kimball, J., Piepmeir, J. R., Koster, R. D., Martin, N., McDonald, K. C., Moghaddam, M., Moran, S., Reichle, R., Shi, J. C., Spencer, M. W., Thurman, S. W., Tsnag, L., and Van Zyl, J.: The Soil Moisture Active Passive (SMAP) mission, P. IEEE, 98, 704-716, 2010.

Ford, T. W., Harris, E., and Quiring, S. M.: Estimating root zone soil moisture using near-surface observations from SMOS, Hydrol. Earth Syst. Sci., 18, 139-154, https://doi.org/10.5194/hess18-139-2014, 2014.

Gaiser, P. W., St. Germain, K. M., Twarog, E. M., Poe, G. A., Purdy, W., Grossman, W., Jones, W. L. Spencer, D., Golba, G., Cleveland, J., Choy, L., and Bevilacqua, R. M.: The WindSat spaceborne polarimetric microwave radiometer: Sensor description and early orbit performance, IEEE T. Geosci. Remote, 42, 2347-2361, 2004.

Hain, C. R., Crow, W. T., Mecikalski, J. R. Anderson, M C., and Holmes, T.: An intercomparison of available soil moisture estimates from thermal-infrared and passive microwave remote sensing, J. Geophys. Res.-Atmos., 166, D15107, https://doi.org/10.1029/2011JD015633, 2011

Hutchinson, J. M. S.: Estimating near-surface soil moisture using active microwave satellite imagery and optical sensor inputs, $\mathrm{T}$. ASAE, 46, 225-236, 2003.

Jackson, T. J., Le Vine, D. M., Hsu, A. Y., Oldak, A., Starks, P. J., Swift, C. T., Isham, J. D., and Haken, M.: Soil moisture mapping at regional scales using microwave radiometry: The South- 
ern Great Plains Hydrological Experiment, IEEE T. Geosci. Remote, 37, 2136-2151, 1999.

Jackson, T. J., Hsu, A. Y., and O’Neill, P. E.: Surface soil moisture retrieval and mapping using high-frequency microwave satellite observations in the Southern Great Plains, J. Hydrometeorol., 3, 688-699, 2002.

Jackson, T. J., Cosh, M. H., Bindlish, R., Starks, P. J., Bosch, D. D., Seyfried, M., Goodrich D. C., Moran, M. S., and Du, J.: Validation of Advanced Microwave Scanning Radiometer Soil Moisture Products, IEEE T. Geosci. Remote, 48, 4256-4272, 2010.

Jackson, T. J., Bindlish, R., Cosh, M. H., Zhoa, T., Starks, P. J., Bosch, D. D., Seyfried, M., Moran, M. S., Goodrich, D. C., Kerr, Y. H., and Leroux, D.: Validation of Soil Moisture and Ocean Salinity (SMOS) Soil Moisture Over Watershed Networks in the US, IEEE T. Geosci. Remote, 50, 1530-1543, 2012.

Kedzior, M. and Zawadski, J.: Comparative study of soil moisture from SMOS satellite mission, GLDAS database, and cosmic rayneutrons measurements at COSMOS in Eastern Poland, Geoderma, 283, 21-31, 2016.

Kerr, Y. H., Waldteufel, P., Wigneron, J. P., Maerinuzzi, J. M., Font, J., and Berger, M.: Soil moisture retrieval from space: The Soil Moisture and Ocean Salinity (SMOS) mission, IEEE T. Geosci. Remote, 39, 1729-1735, 2001.

Klute, A.: Water retention: Laboratory methods, Methods of Soil Analysis: Part 1, in: Physical and Minerological Methods, edited by: Klute, A., American Society of Agronomy and Soil Science Society of America, 635-662, 1986.

Kumar, S. V., Reichle, R. H., Koster, R. D., Crow, W. T., and PetersLidard, C. D.: Role of subsurface physics in the assimilation of surface soil moisture observations, J. Hydrometeorol., 10, 15341547, 2009.

Lakshmi, V., Wood, E. F., and Choudhury, B. J.: Investigation of effect of heterogeneities in vegetation and rainfall on simulated SSM/I brightness tempeatures, J. Appl. Meteorol., 36, 13091328, 1997.

Lettenmaier, D. P., Alsdorf, D., Dozier, J., Huffman, G. J., Pan, M., and Wood, E. F.: Inroads of remote sensing into hydrologic science during the WRR era, Water Resour. Res., 51, 7309-7342, 2015

Liu, Y. Y., Dorigo, W. A., Parinussa, R. M., de Jeu, R. A. M., Wagner, W., McCabe, M. F., Evans, J. P., and van Dijk, A. I. J. M.: Trend-preserving blending of passive and active microwave soil moisture retrievals, Remote Sens. Environ., 123, 280-297, 2012.

Manfreda, S., Lacava, T., Onorati, B., Pergola, N., Di Leo, M., Margiotta, M. R., and Tramutoli, V.: On the use of AMSU-based products for the description of soil water content at basin scale, Hydrol. Earth Syst. Sci., 15, 2839-2852, https://doi.org/10.5194/hess-15-2839-2011, 2011.

Manfreda, S., Brocca, L., Moramarco, T., Melone, F., and Sheffield, J.: A physically based approach for the estimation of root-zone soil moisture from surface measurements, Hydrol. Earth Syst. Sci., 18, 1199-1212, https://doi.org/10.5194/hess-18-1199-2014, 2014

Martinez-Fernandez, J. and Ceballos, A.: Mean soil moisture estimation using temporal stability Analysis, J. Hydrol., 312, 28-38, 2005.

Massari, C., Brocca, L., Barbetta, S., Papathanasiou, C., Mimikou, M., and Moramarco, T.: Using globally available soil moisture indicators for flood modelling in Mediterranean catchments, Hy- drol. Earth Syst. Sci., 18, 839-853, https://doi.org/10.5194/hess18-839-2014, 2014.

McCabe, M. F., Gao, H., and Wood, E. F.: Evaluation of AMSR-Ederived soil moisture retrievals using ground-based and PSR airborne data using SMEX02, J. Hydrometeorol., 6, 864-877, 2005.

Moriasi, D. N., Arnold, J. G., Van Liew, M. W., Bingner, R. L., Harmel, R. D., and Veith, T. L.: Model evaluation guidelines for systematic quantification of accuracy in watershed simulations, T. ASABE, 50, 885-900, 2007.

Njoku, E. G., Jackson, T. J., Lakshmi, V., Chan, T. K., and Nghiem, S. V.: Soil moisture retrieval from AMSR-E, IEEE T. Geosci Remote Sens., 41, 215-229, 2003.

Owe, M., De Jeu, R. A. M., and Holmes, T. R. H.: Multisensor historical climatology of satellite-derived global land surface moisture, J. Geophys. Res.-Earth, 113, F01002, https://doi.org/10.1029/2007JF000769, 2008.

Peterson, A. M., Helgason, W. D., and Ireson, A. M.: Estimating field-scale root zone soil moisture using the cosmicray neutron probe, Hydrol. Earth Syst. Sci., 20, 1373-1385, https://doi.org/10.5194/hess-20-1373-2016, 2016.

Qiu, J., Crow, W. T., Nearing, G. S., Mo, X., and Liu, S.: The impact of vertical measurement depth on the information content of soil moisture time series data, Geophys. Res. Lett., 41, 4997-5004, 2014.

Reece, C. F.: Evaluation of a line heat dissipation sensor for measuring soil matric potential, Soil Sci. Soc. Am. J., 60, 1022-1028, 1996.

Reichle, R., De Lannoy, G., Koster, R., Crow, W., and Kimball, J.: SMAP L4 9 km EASE-Grid Surface and Root Zone Soil Moisture Geophysical Data, Version 2, NASA National Snow and Ice Data Center, 2016.

Rodell, M., Houser, P. R., Jambor, U., Gottschalck, J., Mitchell, K., Meng, C.-J., Arsenault, K., Cosgrove, R., Schaefer, G. L., Cosh, M. H., and Jackson, T. J.: The USDA Natural Resources Conservation Service Soil Climate Analysis Network (SCAN), J. Atmos. Ocean. Tech., 24, 2073-2077, 2007.

Schaefer, G. L., Cosh, M. H., and Jackson, T. J.: The USDA Natural Resources Conservation Service Soil Climate Analysis Network (SCAN), J. Atmos. Ocean. Tech., 24, 2073-2077, 2007.

Seyfried, M. S., Grant, L. E., Du, E., and Humes, K.: Dielectric loss and calibration of the Hydra Probe soil water sensor, Vadose Zone J., 4, 1070-1079, 2005.

Starks, P. J., Heathman, G. C., Jackson, T. J., and Cosh, M. H.: Temporal stability of soil moisture profile, J. Hydrol., 324, 400-411, 2006.

Uppala, S. M., Kållberg, P. W., Simmons, A. J., Andrae, U., Da Costa Bechtold, V., Fiorino, M., Gibson, J.K., Haseler, J., Hernandez, A., Kelly, G. A., Li, X., Onogi, K., Saarinen, S., Sokka, N., Allan, R. P., Anderson, E., Arpe, K., Balmaseda, M. A., Beljaars, A. C. M., Van De Berg, L., Bidlot, J., Bormann, N., Caires, S., Chevallier, F., Dethof, A., Dragosavac, M., Fisher, M., Fuentes, M., Hagemann, S., Hólm, E., Hoskins, B. J., Isaksen, L., Janssen, P. A. E. M., Jenne, R., Mcnally, A. P., Mahfouf, J.-F., Morcrette, J.-J., Rayner, N. A., Saunders, R. W., Simon, P., Sterl, A., Trenbreth, K. E., Untch, A., Vasiljevic, D., Viterbo, P., and Woollen, J.: The ERA-40 re-analysis, Q. J. Roy. Meteor. Soc., 131, 2961-3012, https://doi.org/10.1256/qj.04.176, 2005. 
Tucker, C. J.: Red and photographic infrared linear combinations for monitoring vegetation, Remote Sens. Environ., 8, 127-150, 1979.

Vachaud, G., DeSilnas, A. P., Balabanis, P., Vauclin, M.: Temporal stability of spatially measured soil water probability density function, J. Soil Sci. Soc. Am., 49, 822-828, 1985.

Wagner, W, Lemoine, G, and Rott, H.: A method for estimating soil moisture from ERS scatterometer and soil data, Remote Sens. Environ., 70, 191-207, 1999.

Wagner, W., Scipal, K., Pathe, C., Gerten, D., Lucht, W., and Rudolf, B.: Evaluation of the agreement between the first global remotely sensed soil moisture data with model and precipitation data, J. Geophys. Res.-Atmos., 108, 4611, https://doi.org/10.1029/2003JD003663, 2003.
Wentz, F. J., Meissner, T., Gentemann, C., Hilburn, K. A., and Scott, J.: Remote sensing systems GCOM-W1 AMSR2 Environmental Suite on 0.25 deg grid, Remote Sensing Systems, Santa Rosa, Calfornia, USA, 2014.

Western, A. W., Zhou, S. L., Grayson, R. B., McMahon, T. A., Bloschl, G., and Wilson, D. J.: Spatial correlation of soil moisture in small catchments and its relationship to dominant spatial hydrological processes, J. Hydrol., 286, 113-134, 2004.

Wilson, D. J., Western, A. W., and Grayson, R. B.: Identifying and quantifying sources of variability in temporal and spatial soil moisture observations, Water Resour. Res., 40, W02507, https://doi.org/10.1029/2003WR002306, 2004. 